\title{
Top Bins: An Exploration of Qatar's Use of Sport and Capital to Strengthen Diplomatic Visibility
}

\begin{abstract}
By Anay Katyal
Globalization has given new life to previously benign leisures and vices, allowing states and their respective cultural industries to export (and import) their agenda and visibility. Cultural industries have long played an important role in exercising soft power, and the advent of new communication technologies and newfound spending power amongst the world's working class has only strengthened and opened opportunities on this front. Sports, particularly ones that translate well to global competition, have become a new frontier for states to leverage assets and wealth to construct more prominent messaging surrounding their larger diplomatic work around the globe. By examining Qatari investment in football, track \& field, and other international sports - especially through vehicles like the 2022 FIFA World Cup, the Qatar Investment Authority, Aspire Academy, Paris Saint-Germain, etc. - we are offered a clear understanding as to how Qatar uses its wealth to exploit the global cultural marketplace and entrench itself as an important component of global sporting culture, and the diplomatic utility they aim to reap with such investments.
\end{abstract}

Keywords: Qatar, FIFA, diplomacy, football, capital

\section{Why Sport as a Diplomacy?}

Globalization has given new life to previously benign leisures and vices, allowing states and their respective cultural industries ${ }^{1}$ to export (and import) their agenda and visibility through art and media. Cultural industries have long played an important role in exercising soft power, and the advent of accessible cellular and satellite communication, juxtaposed against the concept of what it means to have a "disposable income" amongst the world's working class - "the towering structures of capital surrounding us make us all unwitting consumers" (Van Grieken and Kantorowicz 2021) - has only strengthened and opened opportunities on this front.

Sports, particularly ones that translate well to global fervor, have become a new frontier for states to leverage their assets and wealth to wield more prominent influence surrounding their larger diplomatic work around the globe. By examining Qatari investment in football, track \& field, and other international sports especially through vehicles like the 2022 FIFA World Cup, Aspire Academy, the Qatar Investment Authority (and by extension, football clubs like Paris SaintGermain, etc.) - we are offered a clear understanding as to how the government of Qatar uses its stately wealth for strategic diplomatic gain. Through a variety of diverse and strategic financial transactions with the West, Qatar can "launder" its

*Researcher, Humboldt-Universität zu Berlin, Germany.

${ }^{1}$ Not to be confused with how Horkheimer coins "culture industries" in Horkheimer et al. (2020). 
diplomatic influence and reputation through legacy fixtures of capital and leisure, alongside the larger global cultural marketplace, for the purpose of integrating itself as a key component of the greater global discourse.

This paper seeks to illustrate how pure, "unadulterated", and massively accumulated wealth can be a deeply integral component in constructing diplomatic leverage, soft power, hard power, and - ergo - the agency to influence global decisions with very little precedent that warrants such power, all thanks to tools of the capital class like globalization. The insidiousness of capital has become a conventional tenet in modern statecraft, and states like Qatar illustrate that. I will explore this fact through the state's sporting investments, the strategy that drove these investments, and the ultimate role they intended to play in the larger landscape of interstate relationships and diplomatic power.

\section{Concrete Financial Strides Made}

The State of Qatar has made significant financial investments in the West, largely through a sovereign wealth fund called the Qatar Investment Authority. Per (Debre 2021), "According to the Las Vegas-based Sovereign Wealth Fund Institute, the Qatar Investment Authority holds assets of \$295 billion" — and the majority of these assets are behemoth institutions based both in the West and Global South, sporting institutions being among the most notable. In this paper I will outline and emphasize the contemporary diplomatic importance of the sporting investments Qatar has approximately made in the past decade.

\section{Tangible Footballing Investments}

The main two vehicles the State of Qatar uses to make these investments are: a. The Qatar Investment Authority (QIA), a "sovereign wealth fund located in Doha Qatar" with $\sim \$ 295,200,000,000$ in state-owned assets (Furtado 2012), b. Aspire Academy, a "state-constructed sports academy with global aim to scout, train, mould Qatari athletes for long-term institutional success" (Gásquez and Royuela 2014), and another example of one of the many aforementioned sporting investments on the part of the state.

QIA had a spending spree in the early aughts, purchasing the likes of Harrod's, placing stakes in major corporations like Volkswagen, investing in property developments in Washington D.C. and New York City (Kabalan 2019), but what was their most important (and mammoth) of an acquisition was their purchase of Paris Saint-Germain Football Club (PSG) in 2011 for \$130 million, with an immediate discretionary cash injection of $\$ 340$ million following (Gásquez and Royuela 2014).

Since this time, QIA has spent 1.3 billion euros on player transfers (Nieto 2021), and the European football market has grown from approximately 16.9 billion euros to 25.2 billion euros - a difference of nearly 8.5 billion euros (Lange 2021). Since their acquisition, PSG has seen its total operating revenue grow from 225 million euros to 542 million euros, and its commercial revenues grow from 
150 million euros to 309 million euros (Sartori 2021). In 2019, PSG signed a shirt sponsorship deal with French multinational hospitality company Accor S. A. (Carp 2019) - whose French-domiciled assets alone are valued at approximately 10.546 billion euros (Accor S. A. 2021) - to the tune of 80 million euros annually, from 2019 to 2032 (Sartori 2021).

In a vacuum, these numbers are meaningless drivel, but in the context of financial incentive for the French Republic, the State of Qatar's role - through its proxy of PSG - cannot remain unstated. The purpose of these figures is to illustrate how deeply important the State of Qatar is to numerous and towering French industries. From hospitality, to tourism, to retail, to cultural capital outright, the sheer size of Qatar's financial contributions (and the fruit they financially bore) to France via PSG alone makes Qatar's domino-like effect on the French economy almost impossible to quantify, indicating a level of geopolitical leverage Qatar has on one of the most important member states of the European Union.

\section{World Cup}

The Fédération Internationale de Football Association, or more commonly known as FIFA, has been the international governing body for the sports of association football (also known as "football" or "soccer") ${ }^{2}$, futsal and beach soccer since 1904 - but a majority of its operating costs are dedicated toward football (FIFA 2020). In that century since the growth of the sport, FIFA has been plagued with allegations of corruption, bribery, "pay-for-play" schemes, and the like. As recently as 2015, former Vice President of FIFA and President of The Confederation of North, Central America and Caribbean Association Football (CONCACAF), Austin "Jack" Warner, had an arrest warrant issued by the U.S. Department of Justice for allegations of wire fraud, racketeering and money laundering (Apuzzo et al. 2017), and following his 2019 indictment for misappropriating 79 million U.S. dollars (Hays 2019), evidence was revealed in 2020 that Warner had directly received financial remuneration in exchange for a pledge to lobby and vote for Russia to host the 2018 World Cup (Coote 2020). While the political agenda behind most of these corrupt allegations differed under various FIFA presidents, a precedent had confidently been set by FIFA and its various bureaucrats that they are not immune to corruption, bribery being the particular issue (Homburg 2008). This is where Qatar's relationship with the event enters.

These allegations of corruption came to a head in the 2000s, ultimately reaching its apex during the bid for the 2018 and 2022 FIFA World Cups. While the process officially started in 2009 with 13 countries in contention, on the 2nd of December, 2010, Russia and Qatar respectively secured hosting rights to the events, and the decision was immediately dogged by allegations of corruption and bribery that had occurred throughout the process (Apuzzo et al. 2017). The allegations (and the simultaneously mounting evidence of unchecked corruption being investigated at FIFA) had reached such geopolitical seriousness that the U.S. Department of Justice officially accused both Russia and Qatar of utilizing entertainment companies as

\footnotetext{
${ }^{2}$ Football will be used to illustrate the sport in question henceforth.
} 
proxies to pay bribes for their host status (United States Department of Justice 2020) and served indictments indicating such.

FIFA's affinity for corruption is not the subject of interrogation within this paper, though. What is key to highlight is Qatar's resolute willingness to spend state money on securing football's biggest event — the World Cup — and global capital's role in enabling their activities. Even beyond the extrapolation one could make of millions of dollars of bribery spent on FIFA bureaucrats, Qatar is also on track to spend approximately 300 billion U.S. dollars in infrastructure projects toward the World Cup alone (Farhad 2013), and the state is expecting the tournament to add 20 billion U.S. dollars to the local economy, the majority of which is made up of either state-owned or Western-partnered enterprise (Foxman 2021). But looking beyond Qatar as a sole actor in enabling this ostentatious spending, identifying the web of entertainment, leisure, financial, etc. corporations that helped contribute, largely thanks to the profit-motivated state of contemporary global finance, is an equally scholarly measure.

The Fox Broadcasting Corporation (Fox), an American commercial broadcast television network owned by media giant and billionaire Rupert Murdoch, had paid 425 million U.S. dollars to secure American broadcasting rights for the 2018 and 2022 FIFA World Cups in a transparent broadcast network bid process. While that was being established, in 2013 FIFA was simultaneously holding talks to move Qatar's World Cup to November (or later), angering Fox due to both the investment it already pledged, and the preexisting broadcast commitments it already held with the National Football League (Rumsby 2013). Two years later, Fox was granted American broadcasting rights for the 2026 edition of the World Cup in a closed-doors, no bid process (Deitsch 2015), raising suspicions of a quid pro quo arrangement between the state and corporation. All of this information points to two key points worth underscoring: 1. FIFA already knew of Qatar as their "chosen" host as early as 2013, adding more water to their bribery allegations, 2. Multinational corporations like Fox ultimately hold the leverage and power in enabling grander Qatar's World Cup initiative.

Fox are likely not the only benefactors of Qatari efforts in securing the World Cup. Multinational infrastructure contractors, textile manufacturers, publishers, travel and leisure conglomerates, etc. all benefited and will continue to benefit directly or indirectly - from the event and the activities that went into lobbying for it. Not only are the major corporate actors involved in the staging of the World Cup evidence of this, but the aforementioned indictment of entertainment companies being used as proxies for bribery also illustrates the willingness of how far capital will go in the name of profit. This is where we find how Qatar successfully used capital, as a singular entity, to achieve its dreams of not only securing the World Cup - but an ultimately reluctantly granted level of respect on the global stage, particularly from the West, as well. 


\section{The Dichotomy between Fan and Capital}

Qatar's approach toward PSG, the World Cup, and football as a whole has fans at a fork in the road regarding their sentiments, such sentiments illustrating the enormity of influence Qatari capital has.

When speaking of the World Cup in particular, fans have significant negative reactions to the event even taking place - so much so that American football fans polled in 2021 indicated 59\% of participants believed the U.S. Men's National Team (USMNT) should boycott the event altogether. Per Danny McLoughlin, the pollster responsible, "There are potentially a number of issues that would lead to fans wanting to boycott the World Cup in Qatar next year. We specifically asked about two sets of human rights issues: the treatment of migrant workers and the treatment of women and the LGBT+ community in Qatar" (Kidd 2021). American fans are one subset of many other contingents of national football team fans expressing concrete rejection of Qatar's World Cup bid, with examples of Norwegian clubs and fans alike organizing and forcing the Norwegian Football Federation to put the prospect of boycotting participation in the event to vote (AFP 2021).

By contrast, Norway's actual footballing federation still rejected the prospect (AFP 2021). No countries or corporations have put out statements condemning the event, and as previously mentioned only increased advertisement and exposure of their participation in the various fixtures of the event. PSG ticket sales have increased to an enormous degree, to the point where Parc Des Princes - PSG's home venue - has regularly had "sold out" signage at its ticket windows since 2017 (Paris Saint-Germain F. C. 2019). What becomes clear here is the separation between classes and their respective class interests. Institutions, which include both private corporations and bureaucratic agencies like football federations, are heavily invested in the success of capital return on the 2022 World Cup, as previously indicated. By contrast, the actual football viewing populace - individuals with remotely no interest in the capital structures that hoist up the World Cup - have shown evidence of, in the very least, implicit rejection or disapproval of the event occurring. The conflict between capital and population values is illustrated, and as precedent indicates, those with vested capital interests have their intentions prioritized over the viewers they supposedly cater to. How powerful capital is in the face of actual citizenry is not to be understated here.

Evidence of mass fan displeasure in Qatar has been quite obvious for years. Despite this, investment in the event continues, advertisements increase, and despite this fan displeasure "the show still goes on," so to speak. The power capital - and the interests of its various gatekeepers - are not to be underestimated, especially when juxtaposed against denizens of nations involved in football. Qatar's own use of its capital resources on the global marketplace to enable the World Cup - and the diplomatic fruit it sowed - showcase how allegedly easy it is to exploit current diplomatic frameworks using nothing more than enormous hoards of wealth. 


\section{One's Enormity of Success Can Hold Others Hostage, and Other Concluding Thoughts}

Efforts in exercising state power, be it soft or hard, often leave client states in coerced positions. Akin to the Chinese Belt and Road Initiative saddling smaller states with financial and diplomatic baggage that will ultimately serve to bring China's foreign policy initiatives to fruition (Van Grieken and Kantorowicz 2021), modern-day Qatar has penetrated the West - particularly components integral to its financial markets - to a point where their voice is one that doesn't go unheard, diplomatically speaking. Much of this is a result of the state's involvement in football, and while as seemingly benign as a sport it is, Qatar has understood how strong of a cultural industry it is, and how to use the tools of global finance to exploit it for geopolitical clout (Furtado 2012).

While comparisons between Chinese debt financing to Pacific states and Qatari involvement in football are arguably hyperbolic, there are functional similarities worth noting that shed light on the decisions Qatar made entering football, and the diplomatic position they have sowed from their actions. As a state today rich in natural gas, commanding approximately $14 \%$ of the world's reserves (only after Iran and Russia), and an active crude oil exporter (Al-Kaabi 2021), Qatar found itself in an excess of wealth after decades as a Middle Eastern backwater nation. While this newfound wealth was mainly directed into the monarchy and its various apparatuses, the general sentiment that permeated Qatar's government was that this wealth and capital should be used as a tool for selfpreservation and sustainable existence as a state (Peterson 2006), especially as Gulf rivalries grow more tenuous geopolitical atmospheres engender themselves in the region (Vertin 2019). These circumstances created fertile ground for the State of Qatar to sow the seeds of opportunity in parking and growing the state's wealth to an extent that both enriched the monarchy and served as an insurance policy against any possible future threats from other Persian Gulf states or Saudi Arabia (Ulrich 2018), which later paid dividends during 2017's Saudi Arabia-led Qatari diplomatic blockade and crisis that created a stranglehold on the availability of goods and services in the country.

Akin to the Chinese government using capital as one of many solutions to their foreign policy initiatives, Qatar took a similar route - but rather than doing so in the name of forming stronger interstate relationships (Van Grieken and Kantorowicz 2021), Qatar purposefully entrenched itself within the economies of major Western countries, so much so that a state cannot hear Qatar say something and not listen. Even beyond the property, shopping, retail, etc. investments made on the part of Qatar by QIA, a sport like football served the country's needs almost perfectly due to how multinational it is. As previously outlined, through PSG and its various relationships with the French entertainment industry, Qatar commands a very strong presence in the French economy. That in itself is diplomatic leverage most countries cannot remotely reach, but PSG fans aren't purely restricted to the French Republic either.

As PSG grew, so did their ability to leverage said growth. Deals have been signed with Air Jordan to sponsor their team shirts, plans to open an apparel store 
in Los Angeles, California have begun, and signing superstar footballers to PSG like Neymar Jr. and Lionel Messi - who command sizeable international fan bases and brands themselves - have resulted in PSG becoming one of the most important football teams in Europe, if not the world. The shirts regularly purchased, the digital content engaged with, the gate receipts generated, the brand value growth have all created an economic web integral to not only the French economy, but the economy of football itself - one that involves the livelihood of multiple countries and carries weight in creating diplomatic inertia. As Qatar has exponentially grown the footballing industry through PSG as a proxy, it has parasitically inserted itself into the economic (and inadvertently diplomatic) affairs of multiple countries (Ulrich 2018). Capital historically garners states' attention, and significant control of capital can almost always guarantee a "seat at the table" in important decision making processes. Qatar has already become a bridge between the East and West, simultaneously brokering deals between Hamas and the Taliban, exerts influence over OPEC, and has become an important ally for the Global North in conflict zones like Afghanistan, Syria, Sudan and Yemen (Vertin 2019). The timing of Qatar's importance and presence in such circumstances prior to their capital expenditures versus before paints a stark picture in the effectiveness of the state's "football diplomacy".

Securing the World Cup, and enriching multiple countries and their local enterprises in the process quite similarly to the paradigm-shifting effect PSG had, serves as the proverbial cherry on top of Qatar's diplomatic dessert. Those who still remember the cultural minutiae of the Great Recession of 2008 remember the phrase "Too big to fail" — in Qatar's case, they utilized football's already globally interconnected nature in conjunction with an already globalized economy to become "Too big to ignore". Though one can argue Qatar has already achieved significant diplomatic visibility and leverage through club football alone thanks to PSG, pulling off the 2022 World Cup - especially considering the difficult circumstances that should have made hosting a near impossibility in the first place - becomes a resolute statement that Qatar is here to stay in most major interstate situations, whether its neighbors or other various adversaries like it or not. Capital has played a major role in reshaping Qatar's relationship with the world around it, and their success in becoming a global power player on a variety of fronts speaks to how insidious forces of capital can be, especially considering how easily they have contravened decades of diplomatic precedent simply at the whim of a state and the agenda of its investments.

\section{References}

Accor S. A. (2021) RevPar key indicators. Accor S. A. AFP (2021, June 21) Norway decides against Qatar World Cup boycott. The Local. Al-Kaabi SS (2021) Gas exporting countries forum - Qatar. GECF. Apuzzo M, Clifford S, Rashbaum WK (2017, May 27) FIFA officials arrested on corruption charges; blatter isn't among them. The New York Times.

Carp S (2019, February 22) PSG confirm Accor shirt sponsorship deal. Sports Media. 
Vol. 8, No. $4 \quad$ Katyal: Top Bins: An Exploration of Qatar's Use of Sport and Capital...

Coote D (2020, April 7) Prosecutors: FIFA executives received bribes for World Cup votes. UPI.

Debre I (2021, May 6) Qatar Finance Minister arrested in corruption investigation. AP News.

Deitsch R (2015, February 12) FIFA grants Fox U.S. TV rights for World Cup through 2026. Sports Illustrated.

Farhad N (2013) Report: behind the mask of the FIFA World Cup 2022. International Union Rights 20(1): 21-22.

FIFA (2020) Annual report 2020. Zürich, Switzerland: FIFA Publications.

Foxman S (2021, June 21) Why Qatar is a controversial venue for 2022 World Cup. Bloomberg.

Furtado A (2012) A look at Qatar's rise to power: using cultural intelligence as our guide. National Military Intelligence Foundation - American Intelligence Journal 30(1): 92-97.

Gásquez R, Royuela V (2014) Is football an indicator of development at the international level? Social Indicators Research 117(3): 827-848.

Hays T (2019, July 10) Ex-Caribbean soccer official hit with $\$ 79$ million judgment. The Washington Post.

Homburg H (2008) Financing world football: a business history of the Fédération Internationale De Football Association (FIFA). Zeitschrift für Unternehmensgeschichte 53(1): 33-69.

Horkheimer M, Adorno TW, Jephcott E, Schmid Noeri G (2020) The culture industry: enlightenment as mass deception. In Dialectic of Enlightenment, 95. Stanford, CA: Stanford University Press.

Kabalan M (2019) Actors, structures and Qatari foreign policy. AlMuntaqa 2(2): 61-82.

Kidd R (2021, May 4) Majority of American soccer fans think USMNT should boycott Qatar World Cup, says survey. Forbes.

Lange D (2021, September 10) Market size of the European professional soccer market from 2006/07 to 2019/20. Statista.

Nieto PS (2021, April 15) Ligue Des Champions: PSG-Manchester City, les meilleurs ennemis se retrouveront en demi-finales. (Champions League: PSG-Manchester City, the best enemies will meet in the semi-finals). Le Parisien.

Paris Saint-Germain F. C. (2019, May 20) Paris Saint-Germain break ticketing records at the Parc Des Princes. Paris Saint-Germain F. C.

Peterson JE (2006) Qatar and the world: branding for a micro-state. The Middle East Journal 60(4): 732-748.

Rumsby B (2013, September 26) FIFA holds secret talks with broadcasters over switching 2022 Qatar World Cup to winter. The Telegraph.

Sartori A (2021, April 28) PSG vs Manchester City: a head-to-head assessment of two Middle Eastern-owned giants. KPMG Football Benchmark on behalf of KPMG International Limited.

Ulrich KC (2018) The gulf on the verge if global challenges and regional dynamics. Insight Turkey 20(2).

United States Department of Justice (2020, April 6) Three media executives and sports marketing company indicted in FIFA case. United States Department of Justice.

Van Grieken BJ, Kantorowicz J (2021) Debunking myths about China: the determinants of China's official financing to The Pacific. Geopolitics 26(3): 861-888.

Vertin Z (2019) Red Sea rivalries: The Gulf, the horn, \& the new geopolitics of the Red Sea. Doha, Qatar: Brookings Institution Doha Center. 